\title{
IDH1/2 Mutation Status by Sequencing
}

National Cancer Institute

\section{Source}

National Cancer Institute. IDH1/2 Mutation Status by Sequencing. NCI Thesaurus. Code C157186.

An indication that the presence or absence of IDH1/IDH2 gene mutations was determined using sequencing techniques. 